\title{
Cognitive dysfunction in cerebellar disorders
}

\author{
S. Shankar', K. Gunasekaran ${ }^{2, *}$, K. Thiruvarut Chelvan ${ }^{3}$ \\ ${ }^{1,2}$ Assistant Professor, ${ }^{3}$ Associate Professor, ${ }^{1}$ Dept. of Psychiatry, ${ }^{2,3}$ Dept. of Neurology, Govt. Mohan Kumaramangalam Medical \\ College Hospital, Salem, Tamil Nadu, India
}

*Corresponding Author:

Email: drgunasekaranneuro@gmail.com

\begin{abstract}
Introduction: Cerebellum is involved not only in motor but also in behavioral and cognitive functions. Cerebellar contribution to non-motor functions has been supported by several animal, human and functional neuroimaging studies.

Aim: The aim of this study was to explore the role of the cerebellum in cognition in patients with cerebellar disorders and to compare with healthy controls.

Materials and Methods: It is Case Control study. 30 cases with cerebellar lesions due to vascular, degenerative, and post infective cause and 30 controls matched for age, sex, and years of education were chosen. International Cooperative ataxia rating scale(ICARS) used to quantify cerebellar dysfunction and Neuropsychological assessment was performed with Rey's Complex Figure Test, Trial Making Test, Rey's Auditory Verbal Learning Test, Stroop Interference Test, Digit span tests, Controlled Oral Word association Test, and Animal Naming Test.

Statistics Analysis: Measures of central tendency and dispersion, tests of significance used for statistical analysis (SPSS version 21.0)

Results: Cases showed deficits in executive function, verbal memory, fluency and attentional processes. Further analysis revealed that cases with bilateral degenerative cause were in general more impaired than those with unilateral vascular lesions.

Conclusion: Altogether, this study confirms that cerebellar damage is associated with significant cognitive impairments. These deficits are correlated with an overall moderate impact on patient's autonomy. Our data favour an indirect participation of the dorsolateral prefrontal and posterior parietal cortical areas to the cerebrocerebellum circuit.
\end{abstract}

Keywords: Cerebellum, Cognition, ICARS-International Cooperative Ataxia Rating Scale, Neurocognitive Dysfunction.

\section{Introduction}

The cerebellum has been traditionally described as an organ involved in maintaining balance, control of muscle tone and movement coordination. However, the damage to the cerebellum does not necessarily result in motor impairments as described by Shmachmann et al, ${ }^{1}$ it can lead to complex cognitive, behavioral and emotional symptoms, which Shmachmann and Sherman et $\mathrm{al}^{2}$ have identified as the Cerebellar Cognitive Affective Syndrome (CCAS).

Grafman et al reported the cognitive disorders among patients with cerebellar pathology conforming clinical descriptions of subcortical dementia. ${ }^{3}$

Cognitive functions are often attributed to the prefrontal cortex, but they are perhaps more appropriately viewed as emerging from the integrated activity of a corticostriatothalamic "loop" and a cerebrocerebellum output channel. Middleton FA et al 1994 described other cognitive impairments frequently reported among patients with cerebellar pathology include working memory ${ }^{4,5}$ and Appollonio IM et al 1993 and few others reported impairment of recall of newly learned information. ${ }^{6-8}$ Botez MI et al 1991 showed a functional disconnection of the cerebellum from the cerebrum, especially from the prefrontal association cortex, is typically implicated in these impairments. ${ }^{9}$ While patients with cerebellar disease have exhibited a variety of cognitive and affective impairments, their disordered executive functioning is particularly notable.

Rapoport M et al 2000 discussed that the cerebellum contains more than half of all the neurons in the brain. ${ }^{10}$ The cerebellum is strongly interconnected with the contralateral cerebral hemispheres in both feed forward and feedback directions. Schmahmann JD et al 1997 and, Middleton FA et al 1997 described higher order cerebral areas, including the dorsolateral prefrontal cortex, as well as the parietal and superior temporal areas, projection via the pons to the cerebellum. The feedback loop connects the deep cerebellar nuclei with cerebral areas, via the red nucleus and the thalamus. ${ }^{11,12}$ Carpenter MD et al $1991^{13}$ discussed the rate of cerebellar afferents is, far higher compared to the efferent, which suggests an integrative role for the cerebellum. Positron emission tomography (PET) and functional magnetic resonance imaging (fMRI) studies have shown cerebellar activity in healthy control subjects in different cognitive tasks.

Though there were good reports of cognitive dysfunction in cerebellar disorder in other countries, there are only few reported in India, also many of the studies assessed one or two domains of cognitive dysfunction in cerebellar disorders, but in this study the goal is to assess the multiple domains of cognitive dysfunctions in cerebellar disorder and cognitive dysfunctions was compared in unilateral and bilateral cerebellar lesions. 


\section{Materials and Methods}

Subjects: The sample was chosen from Neurology department. With the following inclusion and exclusion criteria. 30 consecutive cases and 30 age-and education matched control subjects were enrolled in this study. Convenient sampling technique was used for case selection.

\section{Inclusion criteria}

1. Cases with cerebellar disorder are in the age group between 20-50 yrs.

2. Age matched controls were selected.

3. Cases and controls have minimal education up to $8^{\text {th. }}$

4. Cerebellar disorders include degeneration, infarct, infection and genetic conditions involving only cerebellum were selected as cases.

5. Patients willing to participate and who gave consent to the study.

\section{Exclusion criteria:}

1. Patients with coexisting other CNS lesions

2. Patients and controls with psychiatric illness/MR/ Dementia/substance abuse were excluded from the study.

3. Patient not willing to participate.

4. Patients with age $<20$ and $>50$ were excluded.

5. Patients with education $<8^{\text {th }}$ std were excluded.

\section{Methodology}

The study was approved by institutional ethical committee. The subjects were explained about the nature of the study and informed consent was obtained. Socio demographic details were collected from cases and controls as per pro-forma. Complete physical examination, including psychiatric evaluation was done. Biochemical and laboratory investigations were done. Each patient underwent a detailed neurological examination where cerebellar functionality was studied using ICARS]. Structural brain imaging was performed on all 30 cases using a1.5-T MRI equipment to confirm the diagnosis and to rule out extra cerebellar pathology.

All subjects underwent a battery of neuropsychological tests.

Thirty patients with cerebellar lesions and 30 normal subjects (control group) without a history of neurological or psychiatric illness were enrolled in the study. Fifteen cases had focal cerebellar lesions due to vascular etiology consisting of ischaemic or haemorrhagic stroke, and 15 cases had bilateral involvement due to Degeneration, Cerebellitis and Demyelination.

\section{Tools Used}

\section{Proforma}

Proforma includes personal demographic details, personal history, past history, family history, physical and Mental status examination, Neurological evaluation, biochemical and Neuroimaging investigations.

\section{I-CARS (International Cooperative Ataxia rating Scale) Schmitz-Hubsch T}

This scale has a score of 100 with 19 items and 4 subscales of postural and gait disturbances, limb ataxia, dysarthria, and oculomotor disorders. Higher scores indicate high levels of impairment. The test-retest reliability of the original ICARS shows a high rate of internal consistency by Schoch, B et al 200714

3. Neuro psychological assessment:

a. Attention: Digit span Ramsay, M. C., \& Reynolds, C. R. et al (1995) $)^{15}$

Digit Span is a measure of attention which is composed of two tasks. Digits Forward and Digits Backward. On both tasks, the examiner reads a series of number sequences to the examinee. Each item is scored 0,1 or 2 points.

b. Verbal Memory: Rey Auditory Verbal Learning test (AVLT): The Auditory Verbal Learning Test (AVLT; Schmidt, et al 1996) ${ }^{16}$ was used to assess Verbal Learning and Memory.

The test consists of two lists A and B, with 15 different words in each list. It is a measure of auditory memory. Words in List A are presented at the rate of one word per second during 5 successive trials. After the completion of all the five trials of List A, words in List B are presented once and an immediate recall is taken for the same. The presentation of List B serves as interference and prevents the subject from recalling the words from List $\mathrm{A}$ subsequently from immediate memory. This is followed by the immediate recall of words from List A. After a delay of 20 minutes, words from List A are again recalled to form the delayed recall score. In the recognition trial the Hits are scored separately. Omissions and commissions form the errors.

c. Test of Visuo- constructive Ability Rey Complex Fig. Test

The Visuo Constructive ability was tested using the Rey's Complex Figure Test (Meyers $\&$ Meyers et al, 1995) ${ }^{17}$ Rey developed the test in 1941. The test consists of a complex design which is abstract in nature and cannot be named easily. It has an overall structure and multiple subcomponents within it. The patient has to copy the figure on the paper. The time taken to copy and the number of facts correctly copied resulted in final the score. The correctness of the reproduction is assessed according to the scoring system given in the test manual.

\section{d. Verbal fluency}

Controlled Oral Word Association Test (COWAT): (Benton and Hamsher et al, 1989) ${ }^{18}$ : This test is a measure of phonemic fluency. The subject generates words based on the phonetic similarity of the words. The subjects generates words beginning with the letters F.A.S. Proper nouns and names of the 
numbers should be excluded. The average new words generated over three trials forms the score.

Animal name test (ANT): (LEZAK et al 1995) ${ }^{19}$ : This test is a measure of category fluency which is another form of verbal fluency. The subject generates words which belong to a particular category. Subject is asked to generate the names of animals as many as possible in one minute. The total number of new words generated forms the scores.

\section{e. Executive functions}

Stroop test (Benson and Stuss et al, 1989) ${ }^{20}$ : This test measures the ease with which a perceptual set can be shifted both to conjoin changing demands and by suppressing a habitual response in favor of an unusual one. The pre frontal areas are essential for response inhibition. Three card in which either colour names or symbol is presented in 20 rows and 5 columns. First card has color names printed in black color, second card has $\mathrm{x}$ symbol printed in different colors. And last card has color names blue, green, and red printed in different colors (e.g. red printed in green color). For all the cards time limit given is 45 seconds within which time the number of words read and the number of errors made is noted.

Trail making test: This test measures attention and cognitive flexibility. Formed in Army Individual Test Battery et al. (1944) ${ }^{21}$. Has two parts A and B, both parts of the Trail Making Test consist of 25 circles distributed over a sheet of paper. In Part $\mathrm{A}$, the circles are numbered 1-25, and the patient should draw lines to connect the numbers in ascending order. In Part B, the circles include both numbers (1 13) and letters $(\mathrm{A}-\mathrm{L})$.

\section{Statistical Analysis}

Statistical analysis was conducted using SPSS for Windows version 21.0. For each of the scales and sociodemographic variables the central values and dispersion were calculated. In comparison of the data's, chi-square test for categorical variables and student $t$ test for numerical variables were used.

\section{Results}

Table 1: Shows comparison of socio-demographic profile among cases and controls with no significance

\begin{tabular}{|c|c|c|c|c|}
\hline S. No & Variables & $\begin{array}{c}\text { Cases } \\
(\mathrm{N}=30) n\end{array}$ & $\begin{array}{l}\text { Controls } \\
(\mathrm{N}=30) \mathrm{n}\end{array}$ & P value \\
\hline 1 & $\begin{array}{l}\text { Age } \\
20-30 \\
30-40 \\
40-50\end{array}$ & $\begin{array}{c}8 \\
10 \\
12\end{array}$ & $\begin{array}{c}10 \\
8 \\
12\end{array}$ & .800737 \\
\hline 2 & $\begin{array}{l}\text { Gender } \\
\mathrm{M} \\
\mathrm{F}\end{array}$ & $\begin{array}{l}20 \\
10\end{array}$ & $\begin{array}{c}22 \\
8\end{array}$ & .573138 \\
\hline 3 & $\begin{array}{l}\text { Education } \\
<10 \text { std } \\
>10 \text { std } \\
\text { higher studies }\end{array}$ & $\begin{array}{c}14 \\
13 \\
3\end{array}$ & $\begin{array}{c}11 \\
13 \\
6\end{array}$ & .506617 \\
\hline 4 & $\begin{array}{l}\text { Marital } \\
\text { Unmarried } \\
\text { Married }\end{array}$ & $\begin{array}{l}13 \\
17\end{array}$ & $\begin{array}{l}14 \\
16\end{array}$ & 0.0673 \\
\hline 5 & $\begin{array}{l}\text { Domicile } \\
\text { Rural } \\
\text { Urban }\end{array}$ & $\begin{array}{c}21 \\
9 \\
\end{array}$ & $\begin{array}{l}19 \\
11\end{array}$ & .583882 \\
\hline
\end{tabular}

Table 2: Showing scoring based on International cooperative ataxia rating scale

\begin{tabular}{|l|l|c|}
\hline S. No & \multicolumn{1}{|c|}{$\begin{array}{c}\text { International cooperative ataxia } \\
\text { rating scale }\end{array}$} & $\begin{array}{c}\text { N 30 } \\
(\text { mean })\end{array}$ \\
\hline 1. & Posture and gait disturbances & 15.7 \\
\hline 2. & kinetic function & 17.73333 \\
\hline 3. & Dysarthria & 3.6 \\
\hline 4. & Occulo motor Movement Score & 1.73 \\
\hline & Total & 38.76333 \\
\hline
\end{tabular}


Table 3: Showing Comparison of visual memory, attention, and executive function between cases and controls

\begin{tabular}{|l|l|c|c|c|c|c|c|}
\hline Cognitive tests & Variables & Case & $\begin{array}{c}\text { SD } \\
\text { cases }\end{array}$ & $\begin{array}{c}\text { Normal } \\
\text { controls }\end{array}$ & $\begin{array}{c}\text { SD } \\
\text { control }\end{array}$ & t value & p value \\
\hline \multirow{3}{*}{ Visual memory } & Rey copy & 30.17 & 3.963 & 32 & 1.661 & -4.46 & $.00001^{*}$ \\
\cline { 2 - 8 } & IR & 22.83 & 3.869 & 28.67 & 0.959 & -8.02 & $<.00001^{*}$ \\
\cline { 2 - 8 } & DR & 20.33 & 4.489 & 27 & 0.830 & -8 & $<.00001^{*}$ \\
\hline \multirow{4}{*}{ Attention } & DF & 5.77 & 0.774 & 6.33 & 0.479 & -3.41 & $.00059^{*}$ \\
\cline { 2 - 8 } & DB & 2.63 & 0.806 & 4.13 & 0.435 & -9.26 & $<.0001^{*}$ \\
\hline \multirow{4}{*}{$\begin{array}{l}\text { Executive } \\
\text { functions }\end{array}$} & SW & 67.33 & 6.126 & 77.67 & 2.090 & 8.74 & $<.00001^{*}$ \\
\cline { 2 - 8 } & SC & 44.97 & 5.175 & 56.67 & 2.397 & -11.23 & $<.00001^{*}$ \\
\cline { 2 - 8 } & SWC & 24.33 & 6.070 & 32.00 & 2.197 & -6.5 & $<.0001^{*}$ \\
\cline { 2 - 8 } & TA & 94.53 & 9.298 & 68.93 & 9.861 & 10.35 & $<.00001^{*}$ \\
\cline { 2 - 8 } & TB & 174.33 & 7.738 & 139.50 & 7.916 & 17.23 & $<.0001^{*}$ \\
\hline
\end{tabular}

RC - Rey Copy, IR - Immediate recall, DR - Delayed recall, DF - Digit forward, DB - Digit backward, TA - Trail A, TB - Trail B, SW - Stroop word, SC - Stroop color, SWC - Stroop word color ${ }^{*} \mathrm{p}<0.001-$ significant

In Table 3 Cases found to have low scoring on visual memory, both on immediate and delayed recall domains, Attention and executive function compared to healthy controls, which is statistically significant.

Table 4: Showing comparison of Visual memory, Attention, and Executive function between cases and Healthy Control

\begin{tabular}{|l|l|c|c|c|c|c|}
\hline Cognitive functions & Variables & Case & SD & $\begin{array}{c}\text { Case } \\
\text { controls }\end{array}$ & SD & $\begin{array}{c}\text { p value and } \\
\text { t value }\end{array}$ \\
\hline & Reg & 5.63 & 0.806 & 6.67 & 0.479 & $\begin{array}{c}-6.02 \\
<.00001^{*}\end{array}$ \\
\cline { 2 - 7 } & B & 3.63 & 0.806 & 5.00 & 0.830 & $\begin{array}{c}-6.46 \\
<.00001^{*}\end{array}$ \\
\cline { 2 - 7 } & IR & 5.60 & 0.768 & 5.77 & 0.774 & $\begin{array}{c}-0.82 \\
.203254\end{array}$ \\
\cline { 2 - 7 } & DR & 4.07 & 1.284 & 5.33 & 0.479 & $\begin{array}{c}-5.06 \\
<.00001^{*}\end{array}$ \\
\cline { 2 - 7 } & R & 22.37 & 2.773 & 25.33 & 0.959 & $\begin{array}{c}-5.54 \\
<.00001^{*}\end{array}$ \\
\cline { 2 - 7 } & O & 3.13 & 1.009 & 1.80 & 0.608 & $\begin{array}{c}6.2 \\
<.00001^{*}\end{array}$ \\
\cline { 2 - 7 } & C & 1.07 & 0.640 & 0.70 & 0.469 & $\begin{array}{c}2.54 \\
.006939 *\end{array}$ \\
\hline \multirow{4}{*}{ Verbal fluency } & ANT & 11.27 & 1.618 & 13.53 & 1.252 & $\begin{array}{c}6.07 \\
<.00001 *\end{array}$ \\
\cline { 2 - 7 } & COWAT & 12.23 & 1.813 & 14.33 & 1.268 & $\begin{array}{c}-5.2 \\
<.00001^{*}\end{array}$ \\
\hline
\end{tabular}

REG - Registration, IR - Immediate recall, DR - Delayed recall, DF - Digit forward, DB - Digit backword, TA Trail A, TB - Trail B, SW - Stroop word, SC - Stroop color, R - Recognition, O - Omission, C - Commission, ANT - Animal Naming Test, COWAT - Controlled Oral Word Association Test

$* \mathrm{p}<0.001$

In Table 4 cases had significant impairment in verbal memory and word fluency compared to healthy controls, but did not differ in immediate memory. 
Table 5: Showing Comparison of visual memory, attention, and executive function between cases with unilateral and bilateral involvement

\begin{tabular}{|l|l|c|c|c|c|c|}
\hline $\begin{array}{c}\text { Cognitive } \\
\text { functions }\end{array}$ & Variables & $\begin{array}{c}\text { Unilateral } \\
\text { n-15 }\end{array}$ & SD & $\begin{array}{c}\text { Bilateral } \\
\text { n-15 }\end{array}$ & SD & $\begin{array}{c}\text { p value and } \\
\text { t value }\end{array}$ \\
\hline \multirow{2}{*}{$\begin{array}{l}\text { Visual } \\
\text { memory }\end{array}$} & Rey Copy & 30.4 & 0.830 & 29.93 & 2.685 & $\begin{array}{c}0.64 \\
0.262652\end{array}$ \\
\cline { 2 - 7 } & IR & 23.67 & 4.418 & 122 & 3.162 & $\begin{array}{c}1.19 \\
0.12241\end{array}$ \\
\cline { 2 - 7 } & DR & 21.47 & 4.372 & 19.2 & 4.459 & $\begin{array}{c}1.41 \\
0.085428\end{array}$ \\
\hline \multirow{4}{*}{ Attention } & DF & 5.87 & 0.836 & 5.67 & 0.721 & $\begin{array}{c}0.7 \\
0.244372\end{array}$ \\
\cline { 2 - 7 } & DB & 2.73 & 0.883 & 2.53 & 0.741 & $\begin{array}{c}0.67 \\
0.253916\end{array}$ \\
\hline \multirow{3}{*}{$\begin{array}{l}\text { Executive } \\
\text { dysfunction }\end{array}$} & SW & 68.07 & 6.216 & 66.6 & 6.161 & $\begin{array}{c}0.65 \\
0.260818\end{array}$ \\
\cline { 2 - 7 } & SWC & 47.07 & 5.873 & 42.87 & 3.398 & $\begin{array}{c}2.4 \\
0.01172 *\end{array}$ \\
\cline { 2 - 7 } & TA & 93.8 & 10.441 & 95.27 & 8.301 & $\begin{array}{c}2.73 \\
0.336748\end{array}$ \\
\cline { 2 - 7 } & TB & 172.67 & 8.837 & 176 & 6.324 & $\begin{array}{c}-1.19 \\
0.122411\end{array}$ \\
\hline
\end{tabular}

RC - Rey Copy, IR - Immediate recall, DR - Delayed recall, DF - Digit forward, DB - Digit backward,, TA - Trail A, TB - Trail B, SW - Stroop word, SC - Stroop color, SWC - Stroop word color $* \mathrm{p}<0.001$

Table 5 shows Cases with bilateral involvement shows severe impairment in all tests but not statistically significant. Statistical significance noted in Rey Copy and Stroop Word Color

Table 6: Showing comparison of Verbal memory and Word fluency between cases with unilateral and bilateral involvement

\begin{tabular}{|l|l|c|c|c|c|c|}
\hline $\begin{array}{c}\text { Cognitive } \\
\text { functions }\end{array}$ & Variables & $\begin{array}{c}\text { Unilateral } \\
\mathbf{n - 1 5}\end{array}$ & SD & $\begin{array}{c}\text { Bilateral } \\
\mathbf{n}-15\end{array}$ & SD & $\begin{array}{c}\text { p value and } \\
\text { t value }\end{array}$ \\
\hline & Rey Avg. & 5.73 & 0.883 & 5.53 & 0.741 & $\begin{array}{c}0.67 \\
0.253956\end{array}$ \\
\cline { 2 - 7 } & $\mathrm{B}$ & 3.73 & 0.883 & 3.53 & 0.741 & $\begin{array}{c}0.67 \\
0.253916\end{array}$ \\
\cline { 2 - 7 } & IR & 5.93 & 0.591 & 5.27 & 0.8 & $\begin{array}{c}2.59 \\
0.007455^{*}\end{array}$ \\
\cline { 2 - 7 } $\begin{array}{l}\text { Verbal } \\
\text { memory }\end{array}$ & $\mathrm{DR}$ & 4.2 & 1.374 & 3.93 & 1.224 & $\begin{array}{c}0.56 \\
0.289399\end{array}$ \\
\cline { 2 - 7 } & $\mathrm{R}$ & 22.6 & 2.898 & 22.13 & 2.722 & $\begin{array}{c}0.45 \\
0.326465\end{array}$ \\
\cline { 2 - 7 } & $\mathrm{O}$ & 3.07 & 1.034 & 3.2 & 1.014 & $\begin{array}{c}-0.36 \\
0.36976\end{array}$ \\
\cline { 2 - 7 } & $\mathrm{C}$ & 0.93 & 0.264 & 1.2 & 0.860 & $\begin{array}{c}-1.15 \\
0.130364\end{array}$ \\
\hline \multirow{2}{*}{$\begin{array}{l}\text { Verbal } \\
\text { fluency }\end{array}$} & ANT & 11.47 & 1.766 & 11.07 & 1.486 & $\begin{array}{c}0.67 \\
0.253916\end{array}$ \\
\cline { 2 - 7 } & COWAT & 12.93 & 2.251 & 11.53 & 0.836 & $\begin{array}{c}2.26 \\
0.015935 *\end{array}$ \\
\hline
\end{tabular}

*REY AVG - ReY Average, IR - Immediate recall, DR - Delayed recall, DF - Digit forward, DB - Digit backword, TA - Trail A, TB - Trail B, SW - Stroop word, SC - Stroop color, R - Recognition, O - Omission, C Commission, ANT - Animall Naming Test, COWAT - Controlled Oral Word Association Test $* \mathrm{p}<0.001$ 
Table 6 shows Cases with bilateral involvement shows severe impairment in all tests but not statistically significant. Statistical significance was noted in verbal memory-immediate recall and commission.

Chart 1: Comparison of visual memory, attention, and executive function between Unilateral and Bilateral cases.

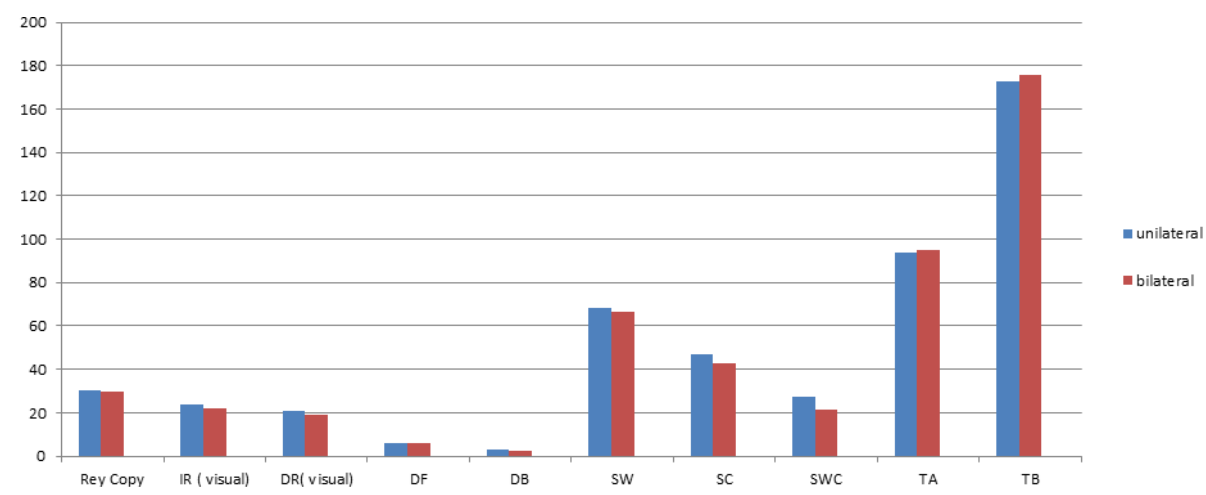

RC - Rey Copy, IR - Immediate recall, DR - Delayed recall, DF - Digit forward, DB - Digit backword,, TA - Trail A, TB - Trail B, SW - Stroop word, SC - Stroop color, SWC - Stroop word color

Chart 2: Showing comparison of Verbal memory and Word fluency between Unilateral and Bilateral cases.

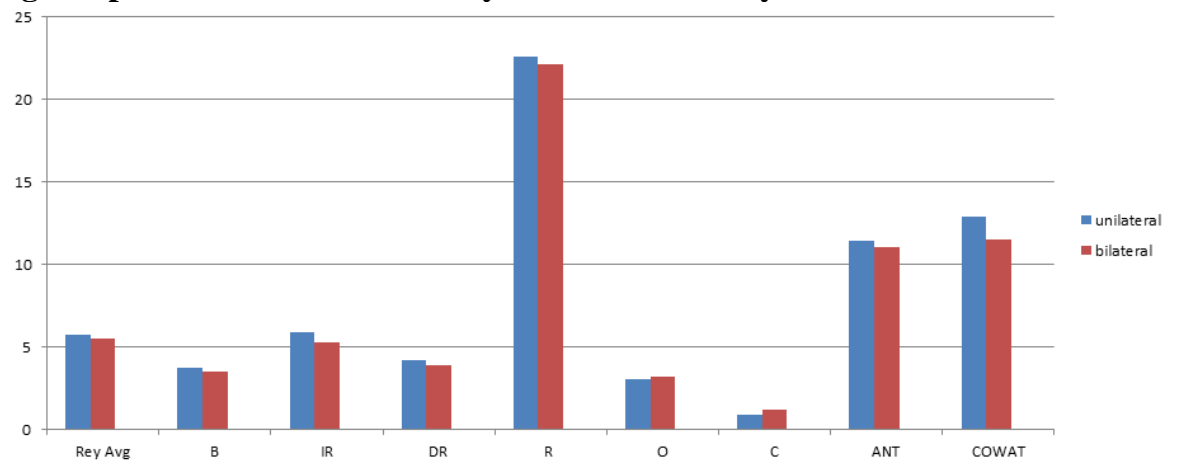

REY AVG - Rey Average, IR - Immediate recall, DR - Delayed recall, DF - Digit forward, DB - Digit backward, TA - Trail A, TB - Trail B, SW - Stroop word, SC - Stroop color, R - Recognition, O - Omission, C Commission, ANT - Animal Naming Test, COWAT - Controlled Oral Word Association Test

\section{Discussion}

On detailed analysis of the socio-demographic profile, majority of cases and controls are of middle age. Two third of them are male, and majority had education less than 10 years, more than half were married. On comparison of cases and controls of both groups, no significant difference was noticed. Table 1 shows the comparison of socio-demographic profile between cases and controls, both are equally matched.

International cooperative ataxia rating scale average score for cases showed posture and gait disturbance score of 15.7, Kinetic function of 17.73, Dysarthria score of 3.6, occult Motor Movement score of 1.73 and the total score was 38.76. Scores given in Table 2.

On analysis of Neurocognitive dysfunction, there is a significantly higher prevalence of visual memory impairment of immediate and delayed recall, executive dysfunction, attentional impairment among cases compared to healthy controls, which was statistically significant shown in the Table 3 .
Significant impairment of Verbal memory impairment of delayed recall and word fluency in cases compared to healthy controls, but no difference was inferred in comparing verbal memory immediate recall between cases and healthy controls which are shown in the Table 4.

There are many studies with similar results. In one study by Grafman et al., 1992 Patients with cerebellar cortical atrophy were found to have impaired executive function demonstrated by increased planning times when performing the Tower of Hanoi Test ${ }^{22}$, and Appollonio et al., 1993 found poor performance on tests of fluency and the initiation/ perseveration subtest of the Mattis Dementia Rating Scale. ${ }^{23}$

Hooper HE et al 1983, and Kaplan Ef et al 1983 found impairment in visual recognition and verbal fluency, Kaplan EF et al used Bostan naming test for assessment of Verbal Fluency. ${ }^{24,25}$

The study results are also consistent with previous studies showing involvement of the cerebellum in attention capacity and executive function, Haarmeier T 
et al 2007 and Bellebaum C et al 2007 found significant impairment in attention and executive function in cerebellar disorders respectively. ${ }^{26,27}$

Fiez JA et al 1992 showed attentional impairment, he specifically reported patients with cerebellar disorder having problem in attentional modulation. ${ }^{28}$ In a study done by Courchesne E et al 1994 reported about impairment in shifting attention in cerebellar patients. ${ }^{29}$

Impairment of verbal memory in correspondence with a study done by Ben-Yehudah G et al 2007, ${ }^{30}$ but in this study there is no significant change in verbal memory immediate recall.

Molinari M et al 1997 showed similar results in verbal fluency and inability to detect one's own errors in tasks such as the verb-for-noun generation paradigm. ${ }^{31}$

Verbal fluency deficits statistically significant. Riva D et al 2000, and Levisohn L 2000 both reported consistent Deficits in fluency after cerebellar lesions. $^{32,33}$ More specifically Molinari M et al 1997 showed one important thing about that results in verbal fluency have been shown to be independent of dysarthria. ${ }^{34}$ Leggio MG et al 2000 showed similar findings in verbal fluency. ${ }^{35}$

Memory impairment also correlated with many studies the results reported by Appollonio et al 1993 indicate that patients with cerebellar degeneration are impaired in effortful memory, but not in implicit and automatic memory processes. ${ }^{36}$ Daum I et al 1993 did not find any memory impairment in patients with cerebellar lesions. ${ }^{37}$ However, Gottwald et al $2003^{38}$ did not think that cerebellar lesions lead to memory impairments per se, but that in our sample those deficits were secondary to the impairment in executive function. By contrast, the main differences were seen in the qualitative aspects of working memory and divided attention.

Silveri MC et al 1994 and Molinari M et al 2007 found impairment in speech and visuospatial functioning respectively. ${ }^{39,40}$ This study demonstrated in visual constructive skills, registration, immediate and delayed recall was significantly impaired. Overall all the cognitive functions were impaired in cerebellar disorders irrespective of etiology and side of lesion, when compared with controls.

Further In this study Cases are categorized into two groups based on one lobe or diffuse involvement .one group is vascular cause with unilateral involvement either right or left side, the other group is degenerative/post infective/demyelinative cause with diffuse bilateral involvement. Comparison by neuropsychological assessment in both groups showed severe impairment of cognitive functions in bilateral lesions in all tests ,especially executive function, immediate recall in verbal memory and word fluency showed statistical significance. Though neurocognitive dysfunctions pertaining to visual memory, attentional impairment, were on higher side in bilateral group than the unilateral one, there is no statistical difference between them (See Table 5 and 6 ). In this study side of the lesion is not included only unilateral or bilateral involvement were taken into account.

Few studies on the impairment due to right or left involvement and the degenerative cause showed similar results.

Malm et al.1998 demonstrated deficits in attention, working memory, visuospatial skills, and cognitive flexibility. ${ }^{41}$ Stroke patients studied by Neau et al and others had deficits in executive function, spatial cognition, attention, and some language tasks. ${ }^{42}$ Single case report by Molinari et al 1997 have shown that patients with right cerebellar infarction develop impairments of linguistic processing including agrammatism and decreased verbal fluency. ${ }^{43}$

In this study it clearly shows that cerebellar dysfunction causes significant impairment in all the cognitive functions, as shown in many studies. More specifically bilateral involvement cause significant impairment that unilateral, and degenerative or demyelinative etiology cause more impairment than vascular etiology.

The neurobehavioral presentation was more pronounced and generalized in those with bilateral or large unilateral infarctions in the posterior lobes in the territory of the posterior inferior cerebellar arteries, and in those with subacute onset of pan cerebellar disorders as in post infectious cerebellitis. They also found that impairment was less evident in patients with more slowly progressive cerebellar degenerations, in the recovery phase (3-4 months) after acute stroke and in those with restricted cerebellar pathology.

Though tumors and spinocerebellar ataxia are not included in this study, there are many studies found severe cognitive dysfunctions in both groups.

Ronning et al 2005 found impaired intelligence, attention, psychomotor speed, verbal memory and visual memory in both groups compared to normal controls, with poor performance in the medulloblastoma group. ${ }^{44}$

One study by de Ribaupierre et al 2008 also supports the notion that cerebellar lesions lead to memory deficits independently from the histological entity of cerebellar tumors. ${ }^{45}$

Similar to that Spinocerebellar ataxia(SCA) type not included in this study because of more extra cerebellar involvement, but many studies found significant impairment in cognitive functions in SCA. Geschwind DH et al 1999 found attentional impairment in SCA. ${ }^{46}$

Gottwald B et al 2004 the cross-lateralization theory hypothesizes that the cerebellum is strongly interconnected by afferent and efferent fibers with the contralateral cerebral hemispheres. ${ }^{47}$

This study and previous study results confirm that cognitive functions are impaired after cerebellar lesions. In accordance with the assumption of 
Courchesne and Allen et al 1997 cerebellar damage did not eliminate the functions but impaired the performance. ${ }^{48}$ The deficits were most pronounced for executive functions and, probably as a consequence, effortful or strategic memory.

This study is consistent with many other study reports and confirmed that cognitive dysfunctions are very common in cerebellar disease irrespective of etiology, almost many of the cognitive functions were impaired and bilateral etiology like degeneration, demyelination cause severe dysfunction compared to unilateral vascular cause. This significant cognitive dysfunction causes impairment in quality of life also in working environment.

Further research is needed to determine whether the right cerebellum is comparable in dominance to the left cerebral hemisphere, acute vs chronic and etiological types which helps to clearly delineate the cognitive science in cerebellum.

\section{Limitations}

Following are considered as limitations in this study:

1. Side of the lesion not taken into account

2. Acute cases taken within 2 weeks of onset of illness, many have pronounced deficits in acute than recovery phase

3. Severe incoordination cases not taken up because of difficulty in performing tasks.

\section{Conclusion}

The role of the cerebellum in higher cognitive functions beyond coordination and motor control has recently attracted significant interest in the scientific community. The modulatory role of the cerebellum in a frontoponto- cerebellar circuit is supported by the fact that neuropsychological disorders are encountered in patients harboring cerebellar lesions independently from the underlying pathology and treatment.

Recognition of the cerebellums important role in behavior and cognition is needed to improve the neuropsychological outcome and quality of life for patients afflicted with cerebellar disorders.

Memory strategies might include use of memory prosthetic devices, such as electronic organizers or notebooks of the types detailed in texts on memory rehabilitation. Rehabilitation of other higher cognitive functions such as visual perceptual-motor integration, executive functioning, judgment, and reasoning are assisted with plans for concretely structuring such activities and developing overt criteria by way of checklists, flowcharts, and other forms of programmed strategies, as has been suggested for the neuropsychological rehabilitation of other etiologies of cognitive dysfunction.

Moreover, it is important to note that the knowledge of cerebellar plasticity may be useful for rehabilitation in cases of cerebral cortical damage in which "higher" forms of learning may not be as accessible. In these cases, a more behavioral approach that focuses on cerebellar-based conditioned responses" may be useful to achieve improvement of relevant behaviors. On the other hand, in cases of cerebellar damage, DeWald JPA and Harrell $\mathrm{M}$ et al described multimodal approaches that do not rely on conditioned associations may be more useful. The relative prognosis in these cases would likely depend not only on the size of the lesions but on the art of the rehabilitation practitioner in differential application of specialized behavioral technique. ${ }^{49,50}$

\section{References}

1. Schmahmann JD, Macmore J, Vangel M. Cerebellar stroke without motor deficit: clinical evidence for motor and non-motor domains within the human cerebellum. Neurosci 2009;162(3):852-861.

2. Schmahmann JD, Sherman JC. The cerebellar cognitive affective syndrome. Brain 1998;121(4):561-579.

3. Grafman J, Litvan I, Massaquoi S, et al: Cognitive planning deficit in patients with cerebellar atrophy. Neurol 1992;42:1493-1496.

4. Middleton FA, Strick P: Anatomical evidence for cerebellar and basal ganglia involvement in higher cognitive function. Sci 1994;266:458-461.

5. Middleton FA, Strick PL: Basal ganglia and cerebellar loops: motor and cognitive circuits. Brain Res Rev 2000;31:236-250.

6. Appollonio IM, Grafman J, Schwartz V, et al: Memory in patients with cerebellar degeneration. Neurol 1993;43:1536-1544.

7. Kish SJ, El-Awar M, Schut L, et al: Cognitive deficits in olivopontocerebellaratrophy: implications for the cholinergic hypothesisofAlzheimer's disease. Ann Neurol 1988;24:200-206.

8. Kish SJ, El-Awar M, Stuss D, et al: Neuropsychological test performance in patients with dominantly inherited spinocerebellar ataxia: relationship to ataxia severity. Neurol 1994;44:1738-1746.

9. Botez MI, Le'veille' J, Lambert R, et al: Single photon emission computed tomography (SPECT) in cerebellar disease: cerebellocerebral diaschisis. Eur Neurol 1991;31:405-412.

10. Rapoport M, van Reekum R, Mayberg H. The role of the cerebellum in cognition and behavior: a selective review. J Neuropsychiatry Clin Neurosci 2000;12:193-8.

11. Schmahmann JD, Pandya DN, The cerebrocerebellar system In: Schmahmann JD, ed. The cerebellum and cognition. International review of neurobiology, San Diego: Academic Press 1997;41:31-60.

12. Middleton FA, Strick PL. Cerebellar output channels. In: Schmahmann JD, ed. The cerebellum and cognition. International review of neurobiology, San Diego: Academic Press 1997;41:61-83.

13. Carpenter MD. Core text of neuroanatomy, 4th edn. Baltimore: Williams \&Wilkins, 1991.

14. Schoch, B; et al. (Nov 2007). "Reliability and validity of ICARS in focal cerebellar lesions". Movement Disorders. 22(15):2162-2169.

15. Ramsay, M. C., \& Reynolds, C. R. (1995). Separate digits tests: A brief history, a literature review, and a reexamination of the factor structure of the Test of Memory and Learning (TOMAL). Neuropsychol Review, 5(3):151-171. 
16. Schmidt, M. (1996). Rey Auditory and Verbal Learning Test: A handbook. Los Angeles, CA: Western Psychological Services.

17. Meyers, J.E. and Meyers, K.R. (1995) Rey Complex Figure Test and Recognition Trial: Professional Manual. Psychological Assessment Resources, Odessa.

18. Benton, A. L., Hamsher, K. de S., \& Sivan, A. B. (1994). Multilingual Aphasia Examination. Iowa City: AJA Associates

19. Lezak, M. D. (1995). Neuropsychological Assessment (3 ed.). New York: Oxford University Press.

20. Stuss, D.T., Benson, D.F. (1986). The frontal lobes. New York: Raven Press. Google Scholar.

21. Army Individual Test Battery. (1944). Manual of Directions and Scoring. Washington, DC: War Department, Adjutant General's Office.

22. Grafman J, Litvan I, Massaquoi S, Stewart M, Sirigu A, Hallett M. Cognitive planning deficit in patients with cerebellar atrophy [see comments]. Neurol 1992; 42: 1493-6. Comment in: Neurol 1993;43:2153-4.

23. Appollonio IM, Grafman J, Schwartz V, Massaquoi S, Hallett M. Memory in patients with cerebellar degeneration. Neurol 1993;43:1536-44.

24. Hooper HE. Hooper Visual Organization Test (VOT) Manual. Los Angeles: Western Psychological Services 1983.

25. Kaplan EF, Goodglass H, Weintraub S. The Boston Naming Test. 2nd ed. Philadelphia: Lea \& Febiger 1983.

26. Haarmeier T, Thier P. The attentive cerebellum - myth or reality? Cerebellum 2007;6:177-83.

27. Bellebaum C, Daum I. Cerebellar involvement in executive control. Cerebellum 2007;6:184-92.

28. Fiez JA, Petersen SE, Cheney MK, et al: Impaired nonmotor learning and error detection associated with cerebellar damage. Brain 1992;115:155-178.

29. Courchesne E, Townsend J, Akshoomoff NA, et al: Impairment in shifting attention in autistic and cerebellar patients. Behav Neurosci 1994;108:848-865.

30. Ben-Yehudah G, Guediche S, Fiez JA. Cerebellar contributions to verbal working memory: beyond cognitive theory. Cerebellum 2007;6:193-201.

31. Molinari M, Leggio MG, Silveri MC: Verbal fluency and agrammatism. Int Rev Neurobiol 1997;41:325-339.

32. Riva D, Giorgi $C$. The cerebellum contributes to higher functions during development: evidence from a series of children surgically treated for posterior fossa tumours. Brain 2000;123:1051-61.

33. Levisohn L, Cronin-Golomb A, Schmahmann JD. Neuropsychological consequences of cerebellar tumour resection in children. Brain 2000;123:1041-50.

34. Molinari M, Leggio MG, Silveri MC. Verbal fluency and agrammatism. In: Schmahmann JD, ed. The cerebellum and cognition. International review of neurobiology, San Diego: Academic Press 1997;41:325-39.

35. Leggio MG, Silveri MC, Petrosini L, et al. Phonological grouping is specifically affected in cerebellar patients: a verbal fluency study. J Neurol Neurosurg Psychiatry 2000;69:102-6.

36. Appollonio IM, Grafman J, Schwartz V, et al. Memory in patients with cerebellar degeneration. Neurol 1993;43:1536-44.

37. Daum I, Ackermann H, Schugens MM, et al. The cerebellum and cognitive functions in humans. Behav Neurosci 1993;107:411-19.

38. Gottwald B, Mihajlovic Z, Wilde B, et al. Does the cerebellum contribute to specific aspects of attention? Neuropsychologia 2003;41:1452-60.
39. Silveri MC, Leggio MG, Molinari M. The cerebellum contributes to linguistic production: A case of agrammatic speech following a right cerebellar lesion [see comments]. Neurol 1994; 44: 2047-50. Comment in: Neurology 1994; 44:2001-5.

40. Molinari M, Leggio MG. Cerebellar information processing and visuospatial functions. Cerebellum 2007;6:214-20.

41. Malm J, Kristensen B, Karlsson T, et al: Cognitive impairment in young adults with infratentorial infarcts. Neurol 1998;51:433-440.

42. Neau JP, Arroyo-Anllo E, Bonnaud V, et al: Neuropsychological disturbances in cerebellar infarcts. Acta Neurol Scand 2000;102:363-370.

43. Molinari M, Leggio MG, Silveri MC: Verbal fluency and agrammatism. Int Rev Neurobiol 1997;41:325-339.

44. Ronning C, Sundet K, Due-Tonnessen B, Lundar T, Helseth E. Persistent cognitive dysfunction secondary to cerebellar injury in patients treated for posterior fossa tumors in childhood. Pediatr Neurosurg 2005;41(1):1521.

45. De Ribaupierre S, Ryser C, Villemure JG, Clarke S. Cerebellar lesions: is there a lateralisation effect on memory deficits? Acta Neurochir 2008;150(6):545-50.

46. Geschwind DH: Focusing attention on cognitive impairment in spinocerebellar ataxia. Arch Neurol 1999;56:20-22.

47. Gottwald B, Wilde B, Mihajlovic Z, Mehdorn HM. Evidence for distinct cognitive deficits after focal cerebellar lesions. J Neurol Neurosurg Psychiatry 2004;75(11):1524-31.

48. Courchesne E, Allen G. Prediction and preparation, fundamental functions of the cerebellum. Learn Mem 1997;4:1-35.

49. DeWald JPA. Sensorimotor neurophysiology and the basis of neurofacilitation therapeutic techniques. In: Brandstater ME, Basmajian 52.JV, editors. Stroke rehabilitation. Baltimore: Williams and Wilkins 1987:10982.

50. Harrell M, Parente F, Bellingrath EG, Lisicia KA. Cognitive rehabilitation of memory: A practical guide. Gaithersburg (MD): Aspen 1992. 